\section{Market study: demand for polyurethanes on the increase}

The market research company Ceresana has conducted a market study aiming at a complete description and analysis of the global PUR market. The analysts forecast that the global demand for PUR will increase, thus leading to considerable expansion of the production capacities - especially in Asia-Pacific. Ceresana also reports that the global isocyanate capacity of around 8.8 million tonnes is expected to increase to more than 3 million tonnes by the year 2020 .

$\mathrm{B}^{\mathrm{s}}$ esides the development of revenues, this new study includes a detailed overview of demand and production as well as the demand for MDI and TDI and the existing and future capacities. The report also provides an outlook on the developments of the individual countries and regions and on the global market dynamics.

Demand, revenues, production, trade and demand for isocyanates are displayed In the framework of this study of the principal 13 countries. Demand for PUR, MDI and TDI is analysed in great detail, divided up into the fields of application furniture/bedding, construction, industrial goods, transportation and other applications.

The study also provides an analysis of the fields in which PUR is used as well as data on demand development, divided up into the regions Western Europe and Eastern Europe, North America, South America, Asia-Pacific, the Middle East and Africa, and gives consumption figures for the principal countries in the individual regions.

The report also includes profiles of MDI and TDI manufacturers, arranged according to contact details, revenues, profit, product range, production locations, profile summary and product-specific information as well as existing and future capacities at individual production locations. Extensive profiles of 23 manufacturers are provided, including BASF, Bayer, Dow Chemical, Huntsman International, Nippon Polyurethane, Wanhua-Borsod Chem and Yantai Wanhua Polyurethanes.

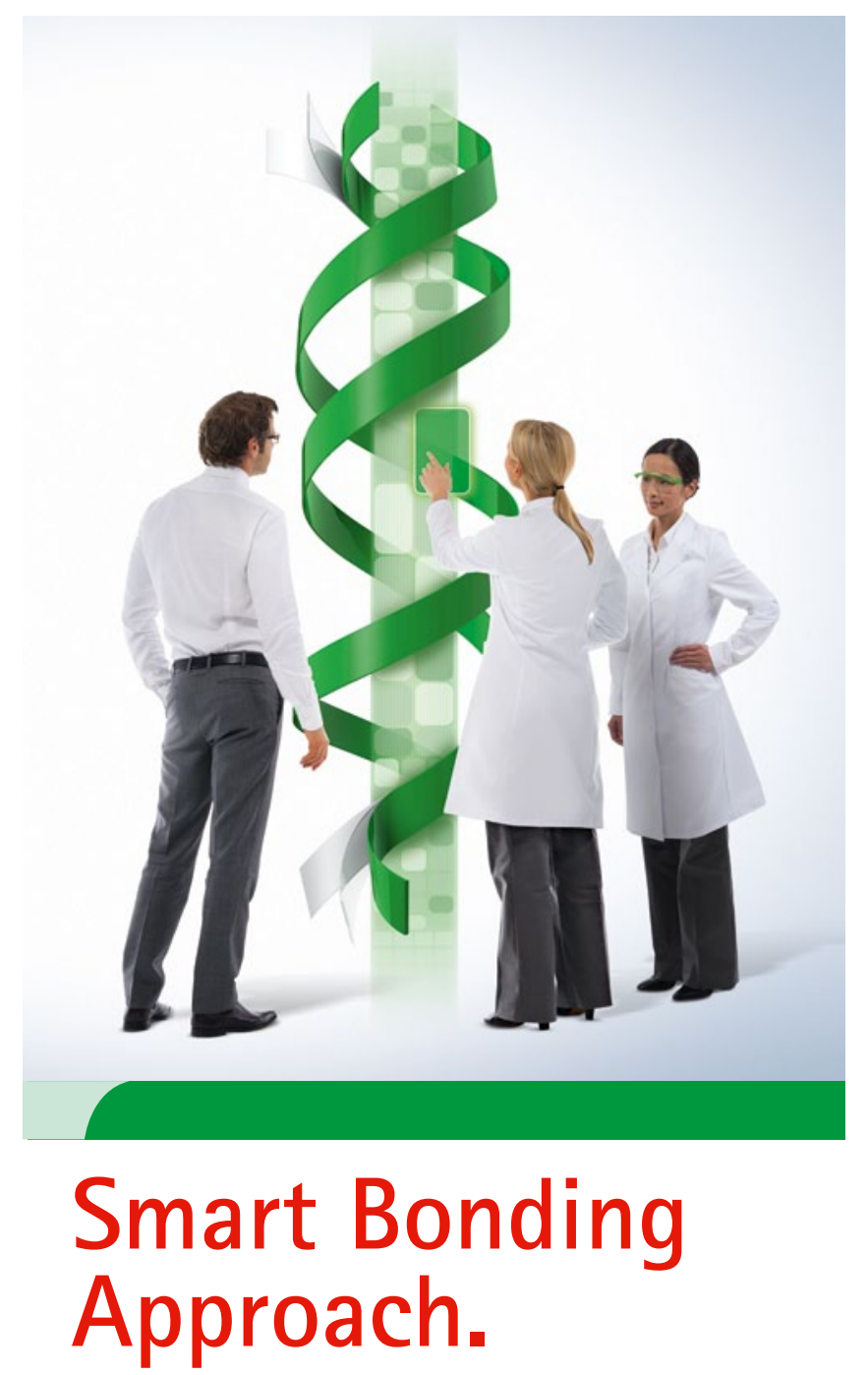

The route to your tailor-made adhesive solution.

What drives us:

We make your world a better place with sustainable and innovative adhesive solutions! The Bonding Engineers stay by your side as competent partners from the moment the first concept is born. Individual adhesive concepts, a convincing product portfolio, efficient process integration and sustainable optimisation safeguard your success.

At Lohmann, we call this philosophy the Smart Bonding Approach. You can call it the perfect route to a tailor-made adhesive solution.

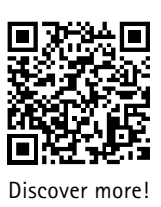

Lohmann GmbH \& Co. KG Phone:+49 2631 34-0 Fax: +49 2631 34-6661 info@lohmann-tapes.com www.lohmann-tapes.com

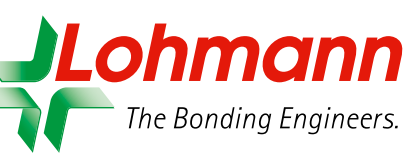

